\title{
Herpetic whitlow in a 39-year-old woman
}

\author{
Arif Ismail MD, Wayne L. Gold MD
}

Cite as: CMAJ 2020 August 31;192:E1010. doi: 10.1503/cmaj.191732

A previously healthy 39-year-old woman presented to the emergency department with a 9-day history of pain, erythema and blistering of the right thumb (Figure 1A) with lymphangitic streaking up the forearm. She reported that years earlier, she had had an episode of oral herpes simplex virus (HSV) infection, but no previous genital HSV infection. On the day of onset, she had left on a planned vacation. She sought medical attention upon arrival and received 2 courses of outpatient antimicrobial therapy for a presumed bacterial infection, without benefit. This prompted admission to hospital, where she underwent 2 surgical irrigation and débridement procedures (Figure 1B). The surgeons noted an absence of purulence. Bacterial cultures were negative, according to patient report.

On return home (day 9 of illness), she sought medical attention at our emergency department for persistent pain and discolouration of the distal digit. We made a presumptive diagnosis of herpetic whitlow and confirmed it by a swab positive for HSV type 1 via polymerase chain reaction (PCR). We prescribed valacyclovir $500 \mathrm{mg}$ twice daily for 7 days, with complete resolution of the infection.

Herpetic whitlow is a cutaneous viral infection of the fingers caused by HSV types 1 and 2. It generally has a self-limited course but recurrences are common. ${ }^{1,2}$ Risk factors include nail trauma, exposure to oral secretions of patients during health care, and previous HSV infection. ${ }^{3}$ The presence of grouped vesicles, absence of tense digital pulp and lack of purulence help to distinguish herpetic whitlow from bacterial paronychia and felon (a bacterial infection of the digital pulp), which are common mimickers. Management consists of oral antiviral therapy with activity against HSV. ${ }^{1-3}$ Surgery is contraindicated because of risks of inoculation into uninfected skin, bacterial superinfection and delayed resolution. ${ }^{2,3}$

In patients presenting with blistering paronychia, a diagnosis of herpetic whitlow should be considered and viral culture or PCR of a sample from an open lesion or a vesicle broken with a small-gauge needle should be performed. Failure to consider this diagnosis may result in unnecessary surgical intervention and antibiotic administration.

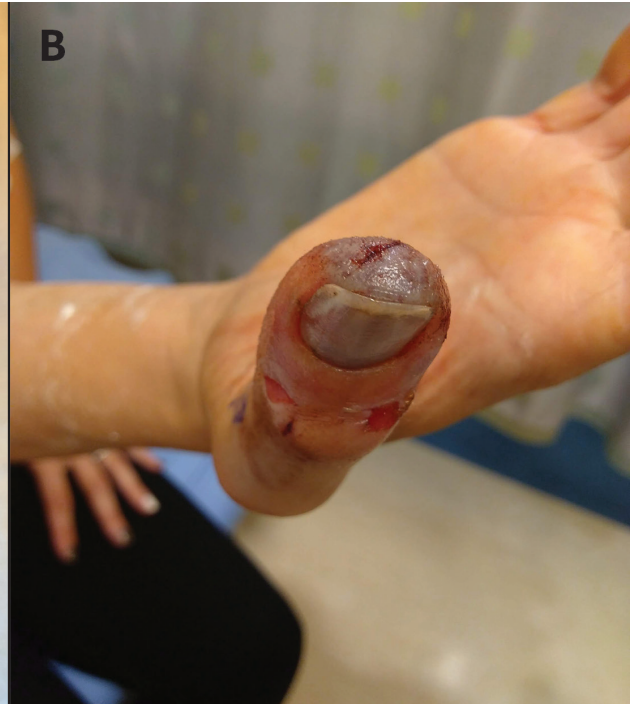

Figure 1: Right thumb of a 39-year-old woman with herpetic whitlow, (A) before the first incision and drainage procedure, showing a blistering paronychia. (B) The same digit after the second surgery and before antiviral therapy was begun.

\section{References}

1. Wu IB, Schwartz RA. Herpetic whitlow. Cutis 2007;79:193-6.

2. Rubright JH, Shafritz AB. The herpetic whitlow. J Hand Surg Am 2011;36:340-2.

3. Shafritz AB, Coppage JM. Acute and chronic paronychia of the hand. J Am Acad Orthop Surg 2014;22:165-74.

\section{Competing interests: None declared.}

This article has been peer reviewed.

The authors have obtained patient consent.

Affiliations: Division of Infectious Diseases, Department of Medicine (Ismail), University of Alberta, Edmonton, Alta; Division of Infectious Diseases, Department of Medicine (Gold), University of Toronto, Toronto, Ont.

Correspondence to: Wayne Gold, wayne.gold@uhn.ca

Clinical images are chosen because they are particularly intriguing, classic or dramatic. Submissions of clear, appropriately labelled highresolution images must be accompanied by a figure caption. A brief explanation (300 words maximum) of the educational importance of the images with minimal references is required. The patient's written consent for publication must be obtained before submission. 